Biogeosciences, 10, 4179-4187, 2013

www.biogeosciences.net/10/4179/2013/

doi:10.5194/bg-10-4179-2013

(C) Author(s) 2013. CC Attribution 3.0 License.

\title{
Nitrous oxide emissions from soil of an African rain forest in Ghana
}

\author{
S. Castaldi ${ }^{1,2}$, T. Bertolini ${ }^{2}$, A. Valente ${ }^{1}$, T. Chiti ${ }^{2}$, and R. Valentini ${ }^{2,3}$ \\ ${ }^{1}$ DISAFRI, Seconda Università di Napoli, via Vivaldi 43, 81100 Caserta, Italy \\ ${ }^{2}$ EuroMediterranean Centre for Climate Change, via Augusto Imperatore 16, 73100, Lecce, Italy \\ ${ }^{3}$ Department for Innovation in Biological, Agro-food and Forest Systems, University of Tuscia, via S. Camillo de Lellis, \\ 01100 Viterbo, Italy
}

Correspondence to: S. Castaldi (simona.castaldi@unina2.it)

Received: 16 October 2012 - Published in Biogeosciences Discuss.: 20 November 2012

Revised: 2 May 2013 - Accepted: 9 May 2013 - Published: 22 June 2013

\begin{abstract}
Recent atmospheric studies have evidenced the imprint of large $\mathrm{N}_{2} \mathrm{O}$ sources in tropical/subtropical lands. This source might be attributed to agricultural areas as well as to natural humid ecosystems. The uncertainty related to both sources is very high, due to the scarcity of data and low frequency of sampling in tropical studies, especially for the African continent. The principal objective of this work was to quantify the annual budget of $\mathrm{N}_{2} \mathrm{O}$ emissions in an African tropical rain forest. Soil $\mathrm{N}_{2} \mathrm{O}$ emissions were measured over 19 months in Ghana, National Park of Ankasa, in uphill and downhill areas, for a total of 119 days of observation. The calculated annual average emission was $2.33 \pm 0.20 \mathrm{~kg} \mathrm{~N}$ $\mathrm{N}_{2} \mathrm{Oha}^{-1} \mathrm{yr}^{-1}$, taking into account the proportion of uphill vs. downhill areas, the latter being characterized by lower $\mathrm{N}_{2} \mathrm{O}$ emissions. $\mathrm{N}_{2} \mathrm{O}$ fluxes peaked between June and $\mathrm{Au}-$ gust and were significantly correlated with soil respiration on a daily and monthly basis. No clear correlation was found in the uphill area between $\mathrm{N}_{2} \mathrm{O}$ fluxes and soil water content or rain, whereas in the downhill area soil water content concurred with soil respiration in determining $\mathrm{N}_{2} \mathrm{O}$ flux variability. The $\mathrm{N}_{2} \mathrm{O}$ source strength calculated in this study is very close to those reported for the other two available studies in African rain forests and to the estimated mean derived from worldwide studies in humid tropical forests $\left(2.81 \pm 2.02 \mathrm{~kg} \mathrm{~N}^{-\mathrm{N}_{2}} \mathrm{O} \mathrm{ha}^{-1} \mathrm{yr}^{-1}\right)$.
\end{abstract}

\section{Introduction}

Tropical forests are a key ecosystem for terrestrial carbon cycling, being the most productive ecosystems on earth (Grace et al., 2001) and accounting for $59 \%$ of the global carbon pool in forests (Dixon et al., 1994). Recent evidence indicates that these ecosystems might have a key role not only in the $\mathrm{C}$ cycle but also in the global atmospheric balance of the greenhouse gas nitrous oxide $\left(\mathrm{N}_{2} \mathrm{O}\right)$. Kort et al.'s (2011) measurements of vertical atmospheric profiles (from surface to $14 \mathrm{~km}$ altitude) between $67^{\circ} \mathrm{S}$ to $85^{\circ} \mathrm{N}$ latitude have shown significant sources of $\mathrm{N}_{2} \mathrm{O}$ in tropical areas with high temporal variability. The available data to support these atmospheric observations are still quite limited in terms of geographical coverage, length of sampling campaign and significance of spatial replication. Most of the available data come from Brasil (Keller et al., 1983, Keller et al., 1988; Verchot et al., 1999; Maddock et al., 2001; Melillo et al., 2001; Davidson et al., 2004; Keller et al., 2005; Neto et al. 2010) and Central America (Matson and Vitousek, 1987; Keller et al., 1993; Keller and Reiners, 1994; Weitz et al., 1998). Only very recently have some data from tropical ecosystems in Asia been published (Verchot et al., 2006; Werner et al., 2006; Yan et al., 2008). Few observations are available for Oceania (Breuer et al., 2000; Kiese and Butterbach-Bahl, 2002; Kiese et al., 2003) and just two studies are available for tropical rain forests in the African continent (Serca et al., 1994; Werner et al., 2007a). Moreover, most of the available studies in remote tropical areas are often based on short campaigns 
of a few days of measurements, which make the annual estimate highly uncertain. Given the wide surface covered by tropical forests, there is a clear need to have a sufficient number of studies to improve our estimates and to help to validate theoretical estimates and downscaling quantifications (Potter et al., 1996; Stehfest and Bouwman, 2006; Werner et al., 2007b). Africa is, in this respect, the least-investigated continent.

The principal objective of this work was to quantify the annual budget of $\mathrm{N}_{2} \mathrm{O}$ emissions in an African tropical rain forest. $\mathrm{N}_{2} \mathrm{O}$ fluxes were sampled monthly, with a frequency of 6 days per month, for 19 months. To better understand the dynamics of $\mathrm{N}_{2} \mathrm{O}$ production, soil $\mathrm{CO}_{2}$ emissions, soil temperature and soil water content were also monitored and their variability related to $\mathrm{N}_{2} \mathrm{O}$ flux variability.

\section{Materials and methods}

\subsection{The study sites}

The study site $\left(05^{\circ} 16^{\prime} 11^{\prime \prime} \mathrm{N}, 02^{\circ} 41^{\prime} 41^{\prime \prime} \mathrm{W}\right)$, located in Ankasa Wildlife Protected Area, is an ancient rainforest with the highest biodiversity in Ghana. The forest has an area of about $500 \mathrm{~km}^{2}$ and in 1976 became a wildlife protected area, to preserve the forests from cutting, slashing and burning, and conversion to agro-ecosystems. A core area of about $343 \mathrm{~km}^{2}$ represents the only protected rain forest area, in an almost pristine state, in Ghana. The mean annual temperature is about $25^{\circ} \mathrm{C}$ and the mean annual precipitation is between $1500-2000 \mathrm{~mm}$, depending on the year, mainly concentrated from March to mid-July and from September to November, with a relative humidity ranging from $75 \%$ to $90 \%$. A relatively dry period generally occurs between December and February (Hall and Swaine, 1981). The landscape is characterized by the presence of hills with an average elevation of $90 \mathrm{~m}$ a.s.l., alternating with steep valleys. Soils are deeply weathered and highly acidic and are classified as Oxisols (Ahn, 1961). Soil, developed on coherent biotite-rich granites of the Cape Coast complex, forms the Ankasa association, consisting of "Abenia" series, the most widespread series on top of the hills, which alternates to the "Ankasa" series, along the slopes. Alluvial soils occupy the bottom of the fluvial valleys. The main characteristics of the soil sampled in uphill and downhill study areas are presented in Table 1. Surface litter $\mathrm{C}$ in the hill top area is $15 \pm 9 \mathrm{MgCha}^{-1}$, and a preliminary estimate of the aboveground biomass, including live and dead wood, is $138-170 \mathrm{Mg} \mathrm{Cha}^{-1}$ (Chiti et al., 2010).

\subsection{Experimental set up}

Soil $\mathrm{N}_{2} \mathrm{O}$ and $\mathrm{CO}_{2}$ flux measurements were carried out during year 2009 and 2010. Sampling started in 2009 in an uphill area where a tower for eddy covariance measurements is located. The micrometeorological station was identified as the center of 4 quadrants (North-east, East-south, Southwest, West-north) and 2 chambers were positioned at a minimum distance of $50 \mathrm{~m}$ from the tower, in each quadrant (8 replicates in all). A second plot of about one hectare was set up in 2010 at the bottom of the valley, where soil conditions are expected to change significantly, in particular soil humidity. Also in this case 8 replicates were used. Chamber position was changed every day to improve the coverage of spatial variability, taking care to insert the chamber base in the ground about $3 \mathrm{~h}$ before starting the measurements so as to avoid false fluxes caused by soil pressure changes and to avoid effects of root mortality and decomposition which might occur in the first weeks following collar insertion into the soil (Keller et al. 2000). Replicates were placed at a minimum distance of $10 \mathrm{~m}$ apart. Within each plot, monthly campaigns of soil-atmosphere gas exchange were carried out, over six consecutive days. Sampling in the uphill area started in April 2009 while in the downhill area sampling started in May 2010, data are reported up to November 2010. The initial experimental set-up included soil temperature and water content measurements undertaken by local micrometeorological station. However, a failure of sensors due to lightning hampered the quality of data. Therefore, from May 2010, soil temperature (HI93510 thermometer, Hanna Instruments Canada Inc., Laval, Quebec) and volumetric soil water content (ThetaProbe ML2, Delta-T Device Ltd, Cambridge, UK) were hand-measured adjacent to each chamber $(0-5 \mathrm{~cm}$ depth), $5 \mathrm{~cm}$ from the chamber edge, at each sampling date. Gas sampling was generally done between 10 and 12 a.m. Soil temperature has an annual average maximal daily variation of about $0.5^{\circ} \mathrm{C}$ at $5 \mathrm{~cm}$ depth and $0.1^{\circ} \mathrm{C}$ at $10 \mathrm{~cm}$ depth (meteorological station at site, 2008-2009 data). Soil water content was expressed as water-filled pore space \% (WFPS) equal to $\left.100 \times \theta_{v}\right) / \varepsilon$, where $\theta_{v}$ is the volumetric water content and $\varepsilon$ is the total porosity ( $\varepsilon=1-$ bulk density/particle density).

\subsection{Gas flux determination}

Gas fluxes were measured using closed static chambers (Hutchinson and Mosier, 1981; Smith et al., 1995) made of PVC collars $(7 \mathrm{~cm}$ high with a diameter of $15 \mathrm{~cm})$, inserted in the soil to about $5 \mathrm{~cm}$ depth, and chamber lids $(20 \mathrm{~cm}$ high with a diameter of $15 \mathrm{~cm}$ ). To determine gas fluxes, gas $(30 \mathrm{ml})$ was sampled, using gas-tight syringes, from the chamber headspace at 0,30 and $60 \mathrm{~min}$ after closure; it was immediately stored in pre-evacuated gas-tight vials $(20 \mathrm{ml})$, slightly overpressurized, which were sealed with thermal glue and shipped for gas chromatographic analysis (TRACE GC ULTRA, THERMO SCIENTIFIC). $\mathrm{N}_{2} \mathrm{O}$ flux rates were determined by linear regression of the three sampling points for each chamber and by applying a temperature and pressure correction. The analytical precision of the GC for standards at ambient concentration was approximately $3 \%$, using one standard deviation as a measure of 
Table 1. Main chemico-physical characteristics $( \pm 1 \mathrm{stdev}, n=6)$ of the soil sampled in the study areas.

\begin{tabular}{lccccccccc}
\hline Site & Depth & Horizon & Sand $^{\mathrm{a}}$ & Silt $^{\mathrm{a}}$ & Clay $^{\mathrm{a}}$ & $\mathrm{BD}^{\mathrm{b}}$ & $\mathrm{pH}^{\mathrm{c}}$ & $\mathrm{C}^{\mathrm{d}}$ & $\mathrm{N}^{\mathrm{d}}$ \\
\hline \multirow{4}{*}{ Uphill } & $\mathrm{cm}$ & & $\mathrm{g} \mathrm{kg}^{-1}$ & $\mathrm{~g} \mathrm{~kg}^{-1}$ & $\mathrm{~g} \mathrm{~kg}^{-1}$ & $\mathrm{Mg} \mathrm{m}^{-3}$ & & $\mathrm{~g} \mathrm{~kg}^{-1}$ & $\mathrm{~g} \mathrm{~kg}^{-1}$ \\
& $0-5$ & $\mathrm{~A}$ & $665 \pm 21$ & $185 \pm 12$ & $150 \pm 15$ & $1.32 \pm 0.12$ & $3.6 \pm 0.3$ & $9.8 \pm 1.12$ & $0.66 \pm 0.21$ \\
& $5-15$ & Bo1 & $580 \pm 20$ & $191 \pm 12$ & $229 \pm 31$ & $1.36 \pm 0.04$ & $4.2 \pm 0.2$ & $1.15 \pm 0.51$ & $0.13 \pm 0.07$ \\
& $15-30$ & Bo1 & $574 \pm 63$ & $171 \pm 20$ & $255 \pm 78$ & $1.35 \pm 0.09$ & $4.5 \pm 0.2$ & $0.86 \pm 0.22$ & $0.11 \pm 0.05$ \\
& $30-50$ & Bo2 & $572 \pm 21$ & $170 \pm 26$ & $258 \pm 27$ & $1.36 \pm 0.13$ & $4.2 \pm 0.2$ & $0.78 \pm 0.19$ & $0.09 \pm 0.04$ \\
Downhill & $0-5$ & A & $734 \pm 19$ & $152 \pm 15$ & $114 \pm 19$ & $1.3 \pm 0.09$ & $4.3 \pm 0.2$ & $2.74 \pm 0.65$ & $0.22 \pm 0.01$ \\
& $5-15$ & A1 & $725 \pm 32$ & $170 \pm 32$ & $105 \pm 23$ & $1.34 \pm 0.11$ & $4.3 \pm 0.2$ & $2.44 \pm 0.09$ & $0.22 \pm 0.02$ \\
& $15-30$ & Bo1 & $668 \pm 25$ & $190 \pm 17$ & $142 \pm 34$ & $1.32 \pm 0.15$ & $4.8 \pm 0.3$ & $2.32 \pm 0.12$ & $0.18 \pm 0.01$ \\
& $30-50$ & Bo2 & $598 \pm 17$ & $186 \pm 21$ & $216 \pm 26$ & $1.38 \pm 0.18$ & $5.0 \pm 0.2$ & $1.10 \pm 0.05$ & $0.10 \pm 0.02$ \\
\hline
\end{tabular}

${ }^{a}$ Determined using the pipette method after destruction of the organic cement using sodium hypochlorite at pH 9 (Mikutta et al., 2005). ${ }^{\mathrm{b}}$ Bulk density determined with the core method (Blake and Hartge 1986). ${ }^{c}$ Measured in deionised water with a sure-flow electrode, using a ratio soil-solution of 1:2.5 (w/w) d Measured by dry combustion (ThermoFinnigan Flash EA112 CHN).

mean error. The analytical set up (Loftfield et al., 1997) allowed both $\mathrm{N}_{2} \mathrm{O}$ and $\mathrm{CO}_{2}$ fluxes to be measured from the same chamber. Gas was loaded on a $2 \mathrm{ml}$ loop connected to a 10-port valve (Valco Europe, Switzerland). A pre-column of $1 \mathrm{~m}$ (O.D. 1/8", 0.08" I.D.), filled with Porapak 80-100 Q and maintained at $60{ }^{\circ} \mathrm{C}$, was connected to the 10 -port valve in order to operate front-flush and back-flush. From the precolumn, the gas passed into the main column (T Porapak 80100 Q, O.D. $1 / 8^{\prime \prime}, 0.08^{\prime \prime}$ I.D., 2 m length), also held at $60^{\circ} \mathrm{C}$ and was then directed to an electron capture detector (ECD) held at $280^{\circ} \mathrm{C}$ for the determination of $\mathrm{CO}_{2}$ and $\mathrm{N}_{2} \mathrm{O}$ concentration. Pure nitrogen was used as carrier gas at a flow rate of $40 \mathrm{~cm}^{3} \mathrm{~min}^{-1}$. A test was made to evidence possible interference of $\mathrm{CO}_{2}$ with $\mathrm{N}_{2} \mathrm{O}$ concentration determination (Wang et al., 2010), by using two $\mathrm{N}_{2} \mathrm{O}$ standards (320 ppb and $5000 \mathrm{ppb}$ ) which were mixed with $\mathrm{CO}_{2}$ at different concentrations (range 1000-10000 ppm), no significant effect of $\mathrm{CO}_{2}$ concentration on the peak area of $\mathrm{N}_{2} \mathrm{O}$ was found. Four concentrations of calibrated standards were used and were injected in duplicate every 20 samples to allow for monitoring instrument drift. The $\mathrm{CO}_{2}$ fluxes determined using this approach can be used for comparative analysis between sites and to identify trends in soil respiration (Yan et al., 2009; Mapanda et al., 2010; Liu et al., 2011) but are not suitable for precisely quantifying soil $\mathrm{CO}_{2}$ efflux and site budgets, due to the length of incubation time which might bring to flux underestimation. For this latter goal $\mathrm{CO}_{2}$ efflux are usually determined by an infrared gas analyzer (IRGA) using dynamic closed or open chambers (Rayment and Jarvis, 1997; Heinemeyer and McNamara, 2010). For this reason no attempt was made in this study to quantify the annual budget of soil $\mathrm{CO}_{2}$ emissions.

\subsection{Statistics}

A two-way analysis of variance was used to compare gas fluxes, soil temperature and water-filled pore space measured in the downhill and uphill plots. A normality test
(Kolmogorov-Smirnov, with Lilliefors correction, Sigma Stat, Jandel Scientific) was performed before running parametric tests (Sigma Stat, Jandel Scientific). When the difference was significant $(P<0.05)$ an "all pairwise" comparison was carried out using the "Student Newman-Keuls test". When normality tests failed, a Kruskal-Wallis ANOVA on ranks was performed. Simple linear regressions, multiple linear regression and non-linear regression analysis were performed to find the relationship between independent and dependent variables (Sigma Stat, Jandel Scientific). Significant differences were at the $P<0.05$ level.

\section{Results}

\subsection{Spatial and temporal variability of $\mathrm{N}_{2} \mathrm{O}$ fluxes}

Single-chamber $\mathrm{N}_{2} \mathrm{O}$ fluxes varied between -0.15 and $29.13 \mathrm{mg} \mathrm{N}_{2} \mathrm{O} \mathrm{m}^{-2} \mathrm{~d}^{-1}$ in the uphill area and -0.53 and $16.62 \mathrm{mg} \mathrm{N}_{2} \mathrm{O} \mathrm{m}^{-2} \mathrm{~d}^{-1}$ in the downhill area. On $46 \%$ of sampling days, the daily spatial variability (range $\mathrm{CV} \%$ 33-288) was higher than the annual temporal flux variability calculated on daily averages (CV\% 110). $\mathrm{N}_{2} \mathrm{O}$ flux showed a marked seasonal variability (Fig. 1a), with daily average fluxes ranging from 0.04 to $8.04 \mathrm{mg} \mathrm{N}_{2} \mathrm{O} \mathrm{m}^{-2} \mathrm{~d}^{-1}$ in the uphill area and from 0.06 to $2.84 \mathrm{mg} \mathrm{N}_{2} \mathrm{O} \mathrm{m}^{-2} \mathrm{~d}^{-1}$ in the downhill area (Fig. 1a). In both environments, the distribution of daily mean values was lognormal. Referring to the period when both environments were monitored, the average daily $\mathrm{N}_{2} \mathrm{O}$ emissions downhill (0.62 $\left.\mathrm{mg} \mathrm{g} \mathrm{N}_{2} \mathrm{O} \mathrm{m}^{-2} \mathrm{~d}^{-} 1\right)$ were significantly lower $(P=$ $0.001)$ than uphill $\left(1.76 \mathrm{mg} \mathrm{g} \mathrm{N}_{2} \mathrm{O} \mathrm{m}^{-2} \mathrm{~d}^{-1}\right)$. The maximum seasonal peak of $\mathrm{N}_{2} \mathrm{O}$ emissions was between June and $\mathrm{Au}-$ gust in both 2009 and 2010 (Fig. 1a). The total annual $\mathrm{N}_{2} \mathrm{O}$ budget was calculated by adding daily means of measured fluxes. The flux of periods in between measured fluxes was calculated as the area delimited by two successive couples of $x, y$ values ( $x$ Julian day, y corresponding $\mathrm{N}_{2} \mathrm{O}$ flux). In the 

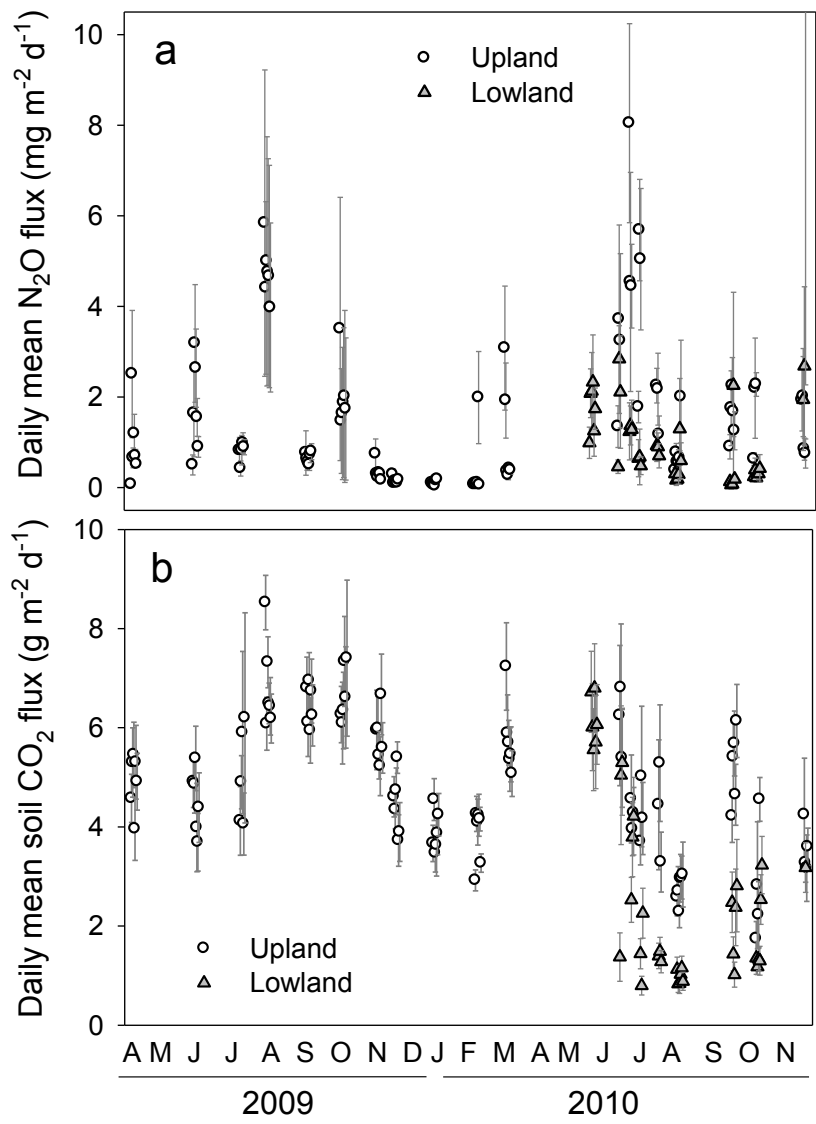

Fig. 1. Daily mean values ( \pm one st dev) of $\mathrm{N}_{2} \mathrm{O}$ fluxes (a) and soil respiration (b) measured in the uphill and downhill areas in 2009 and 2010.

uphill area fluxes were measured from April 2009 to November 2010, so we calculated the cumulative flux for two periods of twelve months, April 2009-March 2010 and October 2009-November 2010. The calculated annual fluxes

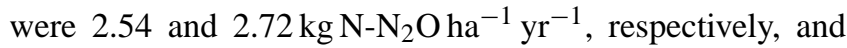
the average was $2.63 \pm 0.23 \mathrm{~kg} \mathrm{~N}_{-} \mathrm{N}_{2} \mathrm{O} \mathrm{ha}^{-1} \mathrm{yr}^{-1}$. The error associated to the total annual emission was calculated using the error propagation formula and was equal to $\sqrt{\sigma^{2} \cdot 365}$, where the daily average standard deviation is derived from all the analyzed days of sampling $\left(0.012 \mathrm{~kg} \mathrm{~N}^{-\mathrm{N}_{2}} \mathrm{O} \mathrm{ha}^{-1} \mathrm{~d}^{-1}\right)$. Comparing the downhill and uphill $\mathrm{N}_{2} \mathrm{O}$ cumulative fluxes over the same period of observation (May to November 2010), the total downhill $\mathrm{N}_{2} \mathrm{O}$ emission was only $44 \%$ of the emission measured in the uphill area. The downhill surface was estimated to be about $20 \%$ of the total surface area of the Ankasa National Park, derived by SRTM DEM at $90 \mathrm{~m}$ resolution (CGIAR - CSI free source). The calculated weighted annual emission per hectare, taking into account the uphill/downhill ratio, was $2.33 \pm 0.20 \mathrm{~N}^{-\mathrm{N}_{2}} \mathrm{O} \mathrm{ha}^{-1} \mathrm{yr}^{-1}$, a value which is within the error estimate of the calculated flux for uphill areas.

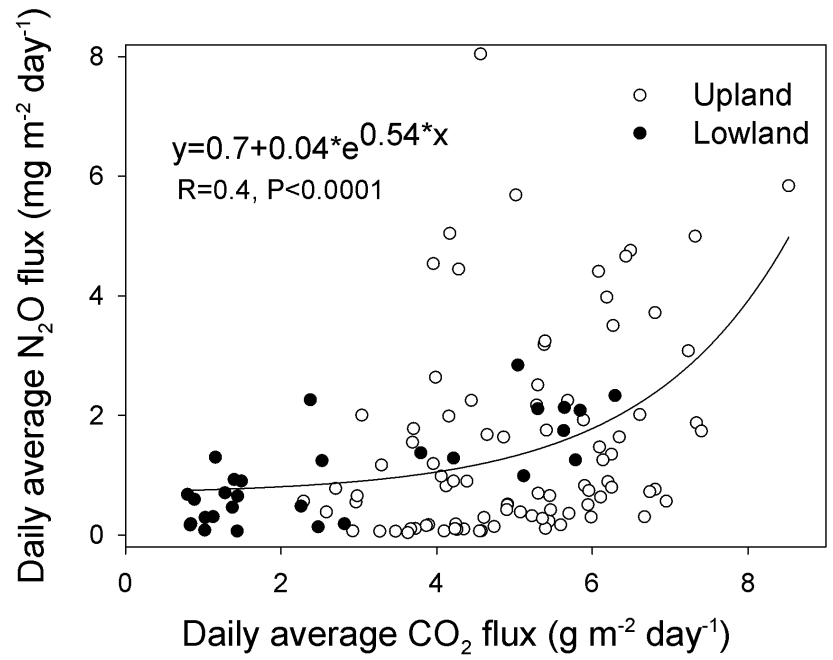

Fig. 2. $\mathrm{N}_{2} \mathrm{O}$ daily average fluxes plotted versus daily average $\mathrm{CO}_{2}$ fluxes measured in the uphill and downhill sites. Plain line is a linear fit of data $\left(R^{2}=0.57, P<0.0001, \mathrm{DF}=58\right)$.

\subsection{Relationship between environmental drivers and $\mathrm{N}_{2} \mathrm{O}$ fluxes}

The potential drivers of $\mathrm{N}_{2} \mathrm{O}$ fluxes measured at site were soil temperature, soil water content, expressed as soil waterfilled pore space, soil $\mathrm{CO}_{2}$ fluxes, monthly air temperature and monthly rainfall, calculated as the average of data from the two weather stations closest to the Ankasa site (TRMM database). The seasonal trend of $\mathrm{N}_{2} \mathrm{O}$ emissions was similar to that of soil respiration (Fig. 1a, b). On a daily basis, higher fluxes of $\mathrm{N}_{2} \mathrm{O}$ emissions corresponded to higher soil respiration rates (Fig. 2). On a monthly basis, the match between temporal trends of the two gases was particularly clear (Fig. 3a, b). The wider seasonal variations of $\mathrm{N}_{2} \mathrm{O}$ emissions, compared with soil respiration, most probably reflected the complex interplay of environmental factors which concurred in $\mathrm{N}_{2} \mathrm{O}$ production and emission. Mean monthly trend values of $\mathrm{N}_{2} \mathrm{O}$ and $\mathrm{CO}_{2}$ emissions did not strictly correspond with trends of average air temperature and total rainfall (Fig. 3c). On a daily basis, variability of $\mathrm{N}_{2} \mathrm{O}$ and $\mathrm{CO}_{2}$ fluxes were related to variations of soil water-filled pore space and soil temperature. For the uphill area, a lognormal relationship was found between both average daily $\mathrm{N}_{2} \mathrm{O}$ emissions and soil respiration and WFPS (Fig. 4a), with a gas flux peak between $30 \%$ and $35 \%$ WFPS, slightly shifted towards higher WFPS values for $\mathrm{N}_{2} \mathrm{O}$ compared to $\mathrm{CO}_{2}$ fluxes (Fig. $4 \mathrm{a}$, b). In the downhill area no significant trend was found between $\mathrm{N}_{2} \mathrm{O}$ or $\mathrm{CO}_{2}$ fluxes and WFPS, although both gases showed a tendency to increase for WFPS values above $50 \%$. However, a significant relationship was found between $\mathrm{N}_{2} \mathrm{O}$ and a linear combination of $\mathrm{CO}_{2}$ fluxes and WFPS $\left(\left[\mathrm{N}_{2} \mathrm{O}\right.\right.$ flux $\left(\mathrm{mg} \mathrm{m}^{-2} \mathrm{~d}^{-1}\right)=-0.907+0.24 \mathrm{CO}_{2}$ flux $\left(\mathrm{g} \mathrm{m}^{-2} \mathrm{~d}^{-1}\right)$ +0.02 WFPS \%], $R^{2}=0.13, P<0.05, N=227$ ). Average 

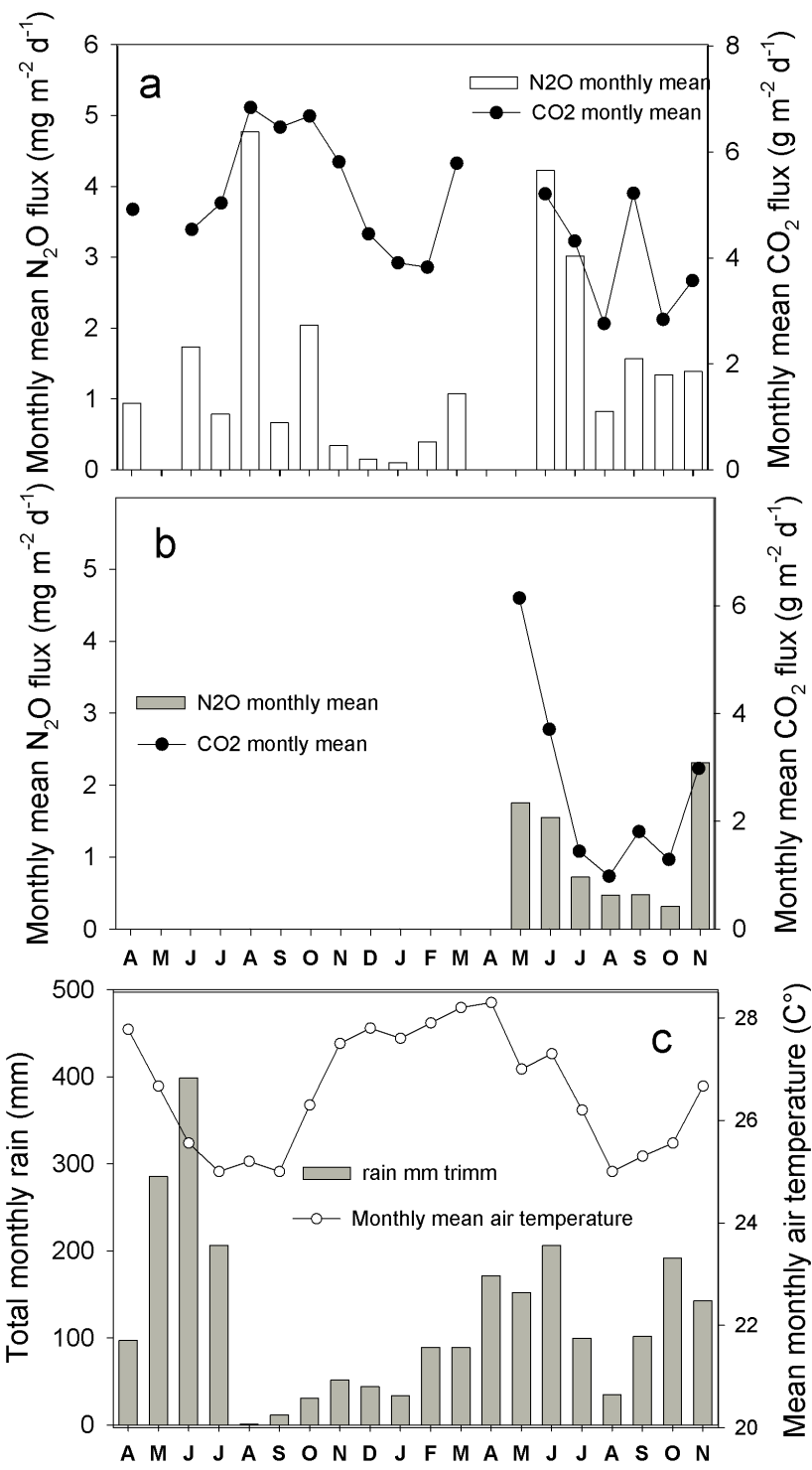

Fig. 3. Monthly mean $\mathrm{N}_{2} \mathrm{O}$ flux (bars) and soil $\mathrm{CO}_{2}$ flux (black dots) calculated for the uphill (a) and downhill (b) areas; mean air temperature and total monthly rainfall (c).

daily $\mathrm{N}_{2} \mathrm{O}$ and $\mathrm{CO}_{2}$ fluxes significantly increased in a range of soil temperatures comprised between 22.5 and $25^{\circ} \mathrm{C}$, the increase being less marked for $\mathrm{CO}_{2}$ fluxes (Fig. 5). The narrow range of temperatures in which a sharp increase of $\mathrm{N}_{2} \mathrm{O}$ flux was observed corresponded to intermediate values of soil WFPS (Fig. 4a). Multilinear regression analysis did not evidence any other significant relationship between analyzed variables and $\mathrm{N}_{2} \mathrm{O}$ emissions.
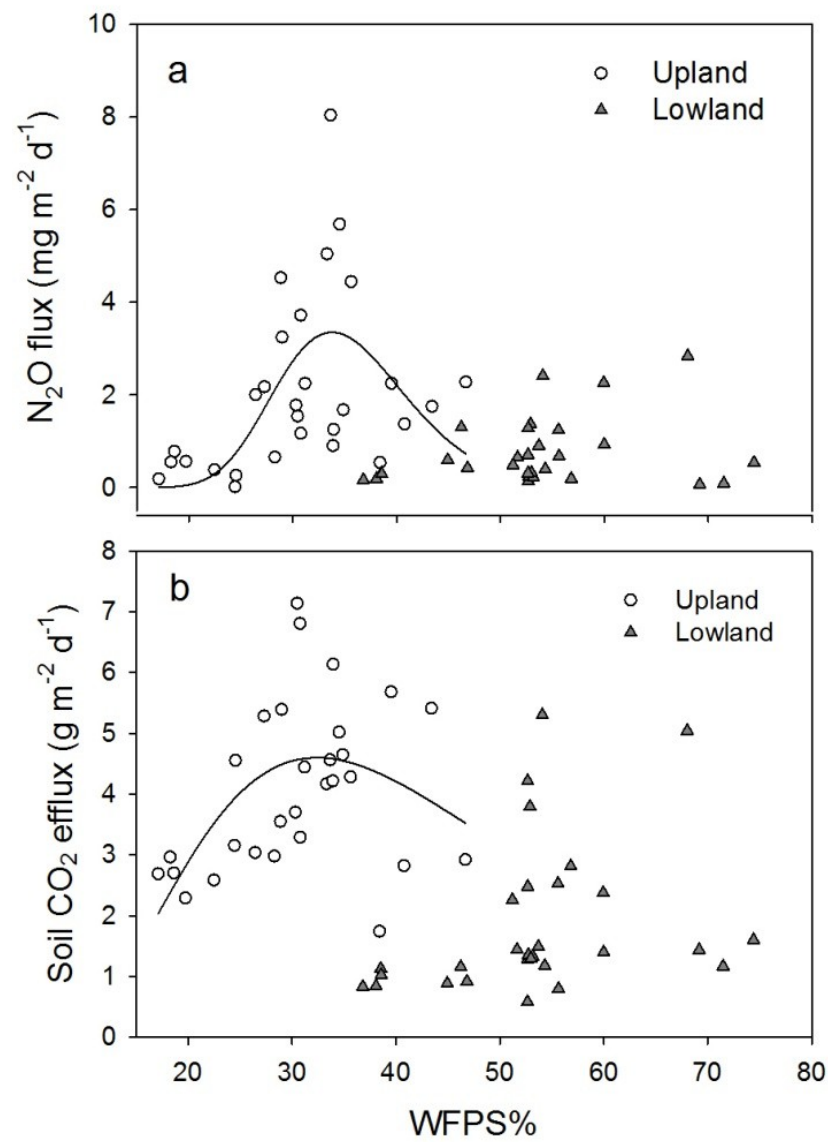

Fig. 4. $\mathrm{N}_{2} \mathrm{O}$ and $\mathrm{CO}_{2}$ daily average fluxes plotted versus values of soil WFPS. The regression lines are lognormal fits of uphill data set of $\mathrm{N}_{2} \mathrm{O}\left((\mathbf{a}) R^{2}=0.31, P=0.007, \mathrm{DF}=29\right)$ and $\mathrm{CO}_{2}\left((\mathbf{b}) R^{2}=\right.$ $0.26, P=0.02, \mathrm{DF}=29)$ fluxes.

\section{Discussion}

The annual budget calculated for the Ankasa rain forest $\left(2.33 \pm 0.20 \mathrm{~kg} \mathrm{~N}^{-N_{2}} \mathrm{O} \mathrm{ha}^{-1} \mathrm{yr}^{-1}\right)$ is very close to the annual $\mathrm{N}_{2} \mathrm{O}$ emission estimates reported by Serca et al. (1994) for a primary rain forest of the Mayombe region in the Congo (2.9 $\mathrm{kg} \mathrm{N}-\mathrm{N}_{2} \mathrm{O} \mathrm{ha}^{-1} \mathrm{yr}^{-1}$ ) and by Werner et al. (2007a) for a mountain rain forest in the Kakamega forest national park in Kenya (2.6 kg N-N $\left.\mathrm{N}_{2} \mathrm{O} \mathrm{ha}^{-1} \mathrm{yr}^{-1}\right)$. The three African sites, including Ankasa, have similar rain regime and acidic soil; Ankasa is characterized by a higher percentage of sand in the soil texture, compared with the other two sites, the Kenya mountain forest has the highest content of soil $\mathrm{C}$ (about twice Ankasa values, in the top 5 centimeters), whereas Ghana and Congo soil $\mathrm{C}$ contents are comparable. Although the observed differences of soil $\mathrm{C}$ and texture might be expected to influence the $\mathrm{N}_{2} \mathrm{O}$ emission rates (Kiese et al., 2005; Werner et al., 2007b), the observed small difference of annual $\mathrm{N}_{2} \mathrm{O}$ emissions among sites indicate that the effect of such influence most probably was within the uncertainty associated to the annual $\mathrm{N}_{2} \mathrm{O}$ emission estimate. On the other 


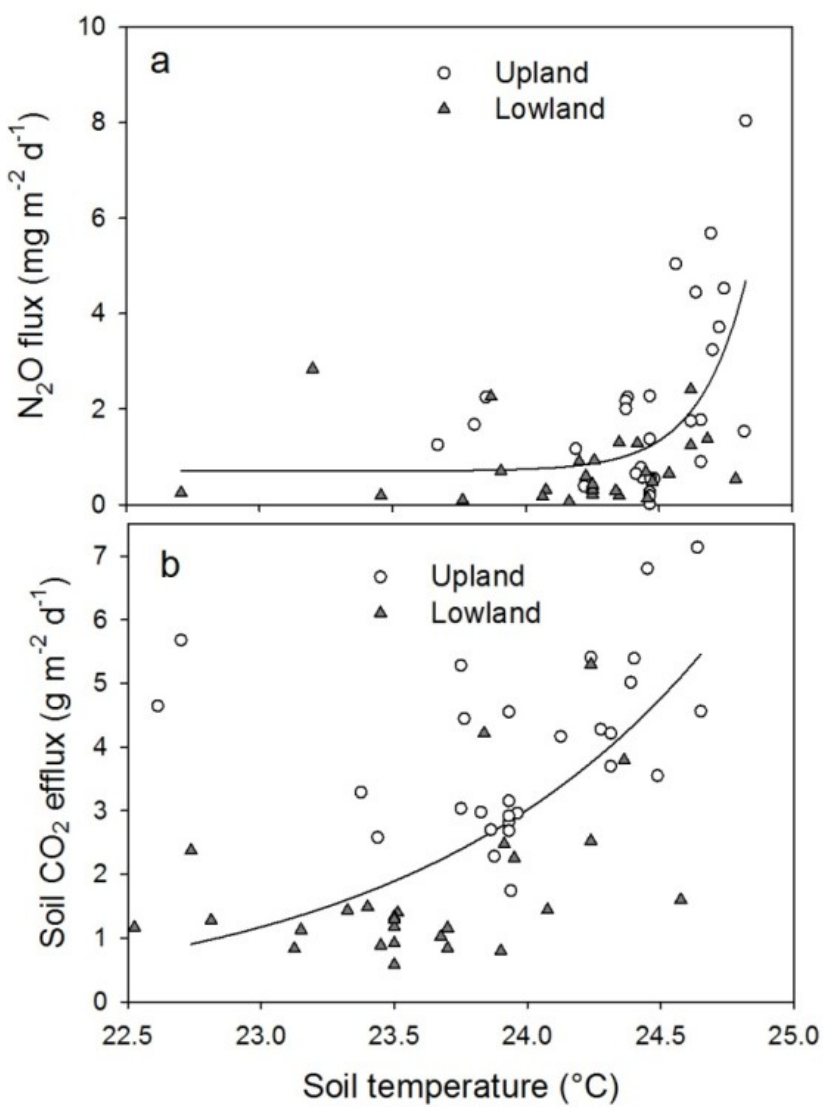

Fig. 5. $\mathrm{N}_{2} \mathrm{O}$ and $\mathrm{CO}_{2}$ daily average fluxes plotted versus soil temperature. The regression lines are exponential fit of both uphill and downhill data sets. $\mathrm{N}_{2} \mathrm{O}$ (a) $R^{2}=0.35, P<0.0001$, DF $=57$ and $\mathrm{CO}_{2}$ (b) $R^{2}=0.46, P<0.0001, \mathrm{DF}=51$.

hand, the comparable annual $\mathrm{N}_{2} \mathrm{O}$ fluxes in the three African sites indicate that key driving mechanisms of $\mathrm{N}_{2} \mathrm{O}$ production are similar in the three tropical rain forests. Both Serca et al. (1994) and Werner et al. (2007a) have evidenced the link between magnitude of $\mathrm{N}_{2} \mathrm{O}$ emissions and the magnitude of $\mathrm{N}$ mineralization activity, indicating the high rates of the latter in rain forests, in spite of acid soil $\mathrm{pH}$, as one of the key factors which supports high $\mathrm{N}_{2} \mathrm{O}$ emission rates. Werner et al. (2007a) also pointed out that while short-term variations of $\mathrm{N}_{2} \mathrm{O}$ might be associated to significant changes in soil moisture, hence to isolated rain events, seasonal $\mathrm{N}_{2} \mathrm{O}$ emission patterns and the annual budget mainly depend on decomposition rates which control $\mathrm{N}$ availability. These observations are in accordance with our results, which indicated a very similar pattern of $\mathrm{N}_{2} \mathrm{O}$ emissions and soil respiration on a monthly average basis and a good correlation between the two variables at daily time step. In the well-drained uphill site, where WFPS never exceeded 50\%, soil respiration was the independent factor, the variability of which best predicted the variability of $\mathrm{N}_{2} \mathrm{O}$ emissions. Soil $\mathrm{CO}_{2}$ emission, namely soil respiration, is the result of combined rates of autotrophic and heterotrophic respiration. The partitioning of these two components in the overall $\mathrm{CO}_{2}$ soil efflux is variable depending on site characteristics, time of the year and of the day (Sotta et al., 2004). Both these components tend to increase with increasing soil temperature and moisture, although in tropical soil $\mathrm{CO}_{2}$ efflux has been reported to be depressed by strong rain events due to both the limiting of gas diffusion and the decrease of soil temperature (Sotta et al., 2004). Although we could not distinguish between autotrophic and heterotropic sources of soil $\mathrm{CO}_{2}$ emissions, we might expect that both processes would have influenced $\mathrm{N}_{2} \mathrm{O}$ production positively. High respiration rates, no matter which organism is involved, tend to decrease soil oxygen content and favor the development of anaerobic hotspots of $\mathrm{N}_{2} \mathrm{O}$ production within aerobic soils (Smith et al., 1990). Higher heterotrophic respiration rates can be expected to coincide with peaks of fresh organic matter input (litterfall), which also represent a source of $\mathrm{N}$ for microbes. In rain forests, peaks of litterfall have been reported to occur mostly at the onset of the rainy season (Muoghalu et al. 1993; De Moraes et al., 1999). Considering that air humidity inside the close and shaded canopy of a rain forest is always quite high, humidity and temperature conditions can generally be considered not limiting for decomposition in the humid tropics, compared with temperate and boreal forest ecosystems, so that a flow of $\mathrm{N}$ which supports nitrification and denitrification processes and $\mathrm{N}_{2} \mathrm{O}$ emissions (Firestone and Davidson, 1989 ) is assured during the whole year. An increase of decomposition rates and mineralization can be expected to coincide with peaks of litter fall and in the first weeks following the onset of heavy precipitation events if they are close to peaks of litter fall (Werner et al., 2007a). The lower fluxes measured in the downhill area, which coincided with much higher WFPS (37-78\%) compared with uphill, might in part be explained by lower soil respiration rates but also by a predominance of reducing conditions during part of the year, leading to further reduction of produced $\mathrm{N}_{2} \mathrm{O}$ to $\mathrm{N}_{2}$ in soil hotspots where WFPS is close to saturation. The occurrence of such hotspots of anaerobic microbial activity is also confirmed by measured $\mathrm{CH}_{4}$ fluxes which showed high emission rates only in the downhill area (Castaldi et al., 2013).

The average annual $\mathrm{N}_{2} \mathrm{O}$ emission estimate derived from the three available studies in African rain forests (Ghana,

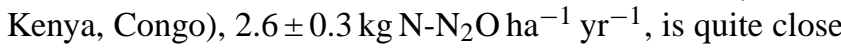
to the global average calculated for tropical humid forests

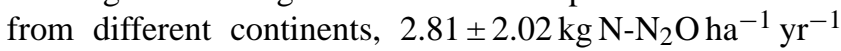
(Table 2), excluding studies where estimates are based on sampling campaigns carried out only in one season (dry or wet). Of the studies reported in Table 2, which represent the most cited literature for humid tropical forests for which a tentative site assessment of $\mathrm{N}_{2} \mathrm{O}$ emission strength is made, about $50 \%$ are characterized by medium to high uncertainty, in particular concerning the temporal frequency of sampling. Only nine of the 41 presented studies show an average sampling frequency higher than 4 samples per month. Within the group of sites characterized by medium/low uncertainty 
Table 2. Annual or seasonal rates (italic) of $\mathrm{N}_{2} \mathrm{O}$ emission $\left(\mathrm{kg} \mathrm{Nha}^{-1} \mathrm{yr}^{-1}\right)$ as reported by authors or calculated (where indicated) from literature studies in humid tropical forests. Reported campaigns occurred only in dry (D) or wet (W) seasons; over a whole year (Y); during periods longer than one year (months are indicated). Arbitrary uncertainty levels are given (explained in Table notes) not as an absolute level of uncertainty but as a comparative indication among studies.

\begin{tabular}{|c|c|c|c|c|c|c|}
\hline Reference & Country & Site & $\begin{array}{l}\text { Sampling } \\
\text { period }\end{array}$ & $\begin{array}{l}\mathrm{N}_{2} \mathrm{O} \text { emission } \\
\mathrm{kg} \mathrm{N} \mathrm{ha}^{-1} \mathrm{yr}^{-1}\end{array}$ & $\begin{array}{c}\mathrm{N}^{\circ} \text { chambers/ } \\
\text { days of sampling }\end{array}$ & $\begin{array}{c}\text { Uncertainty spatial/ } \\
\text { temporal }^{\mathrm{e}}\end{array}$ \\
\hline Breuer et al., 2000 & Australia & Kauri Creek & W-D & 5.36 & $5 / 2084$ & $\mathrm{M} / \mathrm{L}$ \\
\hline Breuer et al., 2000 & Australia & Lake Eacham & W & 1.15 & $5 / 1137$ & $\mathrm{M} / \mathrm{L}$ \\
\hline Castaldi et al., 2013 & Ghana & Ankasa National Park & 19 months & 2.33 & $8-16 / 114$ & $\mathrm{M}-\mathrm{L} / \mathrm{L}$ \\
\hline Davidson et al., 2004 & Brasil & Tapajos National Forest & D-W, 5ys & 1.4 & $18 / 20$ & $\mathrm{M} / \mathrm{H}$ \\
\hline Keller and Rainers 1994 & Costa Rica & La Selva, prim for. & $\mathrm{Y}$ & $5.86^{\mathrm{d}}$ & $8 / 12$ & $\mathrm{M} / \mathrm{M}$ \\
\hline Keller et al., 1993 & Costa Rica & La Selva & $\mathrm{Y}$ & 6 & $8 / 12$ & $\mathrm{M} / \mathrm{M}$ \\
\hline Keller et al., 2005 & Brasil & Tapajos Forest Ultisol & $2 \mathrm{Ys}$ & 1.4 & $8 / 31$ & $\mathrm{M} / \mathrm{M}$ \\
\hline Keller et al., 2005 & Brasil & Tapajos Forest Oxisol & $2 \mathrm{Ys}$ & 6.5 & $8 / 31$ & $\mathrm{M} / \mathrm{M}$ \\
\hline Kiese, Butterbach-Ball, 2002 & Australia & Kauri Creek & D-W & 4.36 & $5 / 400$ & $\mathrm{M} / \mathrm{L}$ \\
\hline Kiese, Butterbach-Ball, 2002 & Australia & Bellender Ker & D-W & 7.45 & $5 / 351$ & $\mathrm{M} / \mathrm{L}$ \\
\hline Kiese, Butterbach-Ball 2002 & Australia & Pin Gin Hill & D-W & 6.89 & $5 / 451$ & $\mathrm{M} / \mathrm{L}$ \\
\hline Luizao et al., 1989 & Brazil & Terra Firme & $\mathrm{Y}$ & $1.9^{\mathrm{c}}$ & $8 / 11$ & $\mathrm{M} / \mathrm{H}$ \\
\hline Maddock et al., 2001 & Brasil & Tinguà biol. Res & $\mathrm{Y}$ & $3.14^{\mathrm{c}}$ & $5 / 21$ & $\mathrm{M} / \mathrm{M}$ \\
\hline Matson et al., 1990 & Brazil & Manaus, Oxisol & $\mathrm{W}$ & $0.86^{\mathrm{c}}$ & $8 / 10$ & $\mathrm{M} / \mathrm{M}$ \\
\hline Matson et al., 1990 & Brazil & Manaus, Ultisol & W & $0.19^{\mathrm{c}}$ & $8 / 4$ & $\mathrm{M} / \mathrm{H}$ \\
\hline Matson et al., 1990 & Brazil & Manaus, Spodsol & $\mathrm{W}$ & $0.07^{\mathrm{c}}$ & $8 / 2$ & $\mathrm{M} / \mathrm{H}$ \\
\hline Matson and Vitousek 1987 & Costa Rica & La Selva & $\mathrm{W}$ & $1.2^{\mathrm{c}}$ & $8 / 2$ & $\mathrm{M} / \mathrm{H}$ \\
\hline Matson and Vitousek 1987 & Costa Rica & La Selva & $\mathrm{W}$ & $1.66^{\mathrm{c}}$ & $8 / 2$ & $\mathrm{M} / \mathrm{H}$ \\
\hline Matson and Vitousek 1987 & Costa Rica & Turialba & $\mathrm{W}$ & $1.14^{\mathrm{c}}$ & $10 / 1$ & $\mathrm{M} / \mathrm{H}$ \\
\hline Melillo et al., 2001 & Brazil & Rondonia & $\mathrm{Y}$ & 1.94 & $3 / 11$ & $\mathrm{H} / \mathrm{H}$ \\
\hline Nepstad et al., 2002 ${ }^{\mathrm{a}}$ & Brasil & Tapajos National Forest & 34 months & 2.3 & $18 / 13$ & $\mathrm{~L} / \mathrm{H}$ \\
\hline Neto et al., 2010 & Brasil & Picinguaba & $\mathrm{Y}$ & 2.2 & $4 / 12$ & $\mathrm{H} / \mathrm{M}$ \\
\hline Neto et al., 2010 & Brasil & Santa Virginia & $\mathrm{Y}$ & $0.9^{\mathrm{c}}$ & $4 / 12$ & $\mathrm{H} / \mathrm{M}$ \\
\hline Weitz et al., 1998 & Costa Rica & La Selva, sec for,dystrop & 13 months & $1.42^{\mathrm{b}}$ & $8 / 20$ & $\mathrm{M} / \mathrm{M}$ \\
\hline Weitz et al., 1998 & Costa Rica & La Selva, sec for, eutrop & 14 months & $1.28^{\mathrm{b}}$ & $8 / 22$ & $\mathrm{M} / \mathrm{M}$ \\
\hline Werner et al., 2007 & Kenya & Kakamega forest & D-W & 2.6 & $6 / 347$ & $\mathrm{M} / \mathrm{L}$ \\
\hline
\end{tabular}

${ }^{a}$ same site of Davidson et al 2004; ${ }^{b}$ calculated from annual average; ${ }^{c}$ extrapolated from monthly measurements; ${ }^{\mathrm{d}}$ extrapolated from mean estimates for the sampling period; e spatial uncertainty classified as high $(\mathrm{H})$ when no chambers $<5$, medium $(\mathrm{M})$ when $5<$ no. ch $<10$, low $(\mathrm{L})$ when no. ch $>10$; temporal uncertainty classified as high $(\mathrm{H})$ when only one season is sampled or when over the year we have less than 1 measurement per month, medium (M) when sampling frequency is between 1 and 4 days per month, low (L) when sampling frequency is higher than 4 days per month.

the range of observed fluxes varies from 0.94 to $7.45 \mathrm{~kg} \mathrm{~N}$ $\mathrm{N}_{2} \mathrm{Oha}^{-1} \mathrm{yr}^{-1}$. All the sites which show fluxes higher than $3 \mathrm{~kg} \mathrm{~N}-\mathrm{N}_{2} \mathrm{O} \mathrm{ha}^{-1} \mathrm{yr}^{-1}$ are characterized by annual total rainfall higher than $2000 \mathrm{~mm}$, with the sole exception of Kauri Creek site in Australia (Table 2), hence higher than rainfall at Ankasa site. Rainfall represents both a proximal and distal factor which exert a positive control (stimulation) on $\mathrm{N}_{2} \mathrm{O}$ emission, because it influences soil water-filled pore space,
NPP, and decomposition rates. Moreover, at increasing rainfall rates there is a progressive reduction of the length of periods with clear dry conditions, which are less favorable for $\mathrm{N}_{2} \mathrm{O}$ production. 


\section{Conclusions}

Results showed that the rain forest in Ghana has annual emission rates very close to other rain forest sites of Central Africa characterized by similar rainfall conditions. Fluxes were characterized by high temporal variability, which supported the extreme importance of adequate sampling frequency in this natural environment. Moreover, the study also showed the importance of spatial coverage, with valley areas having statistically different fluxes from uphill areas. This is a common feature of many tropical landscapes which need to be taken into account when scaling up.

Acknowledgements. The present work was support by the CarboAfrica project and ERC grant GHG Africa no. 247349, we thanks Justice John Mensah for gas sampling, Michele Riondino for support with gas analysis and Mary Claire Barber and David Whitworth for English revision.

Edited by: X. Wang

\section{References}

Ahn, P. M.: Soils of the lower Tano basin, south-western Ghana, Ministry of Food and Agriculture, Scientific Services Division, Soil and Land-use Survey Branch, Kumasi, 266, 1961.

Blake, G. R. and Hartge, K. H.: Bulk Density, in: Methods of Soil Analysis, Part I. Physical and Mineralogical Methods, edited by: Klute, A., Agronomy Monograph no. 9, 2 Edn., 363-375, 1986.

Breuer, L., Kiese, R., and Butterbach-Bahl, K.: $\mathrm{N}_{2} \mathrm{O}$ emissions from tropical forest soils of Australia, J. Geophys. Res., 105, 2635326367, 2000.

Castaldi, S., Bertolini, T., Santini, M., Thongo M'Bou, A., De Grandcourt, A., Nicolini, G., and Valentini, R.: Hotspots of $\mathrm{N}_{2} \mathrm{O}$ and $\mathrm{CH}_{4}$ emissions in tropical ecosystems, Geophys. Res. Abs., 15, EGU2013-3170-1, 2013.

Chiti, T., Certini, G., Grieco, E., and Valentini, R.: The role of soil in storing carbon in tropical rainforests: the case of Ankasa Park, Ghana, Plant Soil, 331, 453-461,2010.

Davidson, E. A., Nepstad, D. C., Ishida, F. Y., and Bando, P. M.: Effects of an experimental drought and recovery on soil emissions of carbon dioxide, methane, nitrous oxide, and nitric oxide in a moist tropical forest, Glob. Change Biol., 14, 2582-2590, 2004.

De Moraes, R. M., Carvalho, W.,B., and Struffaldi-DeVuono, Y.: Litterfall and litter nutrient content in two Brazilian Tropical Forests, Rev. Brasil. Botanica, 22, 9-16, 1999.

Dixon, R. K., Brown, S., Houghton, R. A., Solomon, A. M., Trexler, M. C., and Wisniewski, J.: Carbon pools and flux of global forest ecosystems, Science, 263, 185-190, 1994.

Firestone, M. K. and Davidson, E. A.: Microbiological basis of $\mathrm{NO}$ and $\mathrm{N}_{2} \mathrm{O}$ production and consumption in soil, in: "Trace Gas Exchange between Terrestrial Ecosystems and the Atmosphere", edited by: Andreae, M. D. and Schimel, D. S., 7-22, Wiley, Berlin, 1989.

Grace, J., Malhi, Y., Higuchi, N., and Meir, P.: Productivity and carbon fluxes of tropical rain forests, in: Terrestrial Global Pro- ductivity: Past, Present and Future, edited by: Mooney, H. and Saugier, B., 401-426, Academic Press, 2001.

Hall, J. B. and Swaine, M. D.: What is forest, in: Distribution and ecology of vascular plants in a tropical rain forest, Forest vegetation in Ghana, edited by: Junk, W., 3-29, The Hague, The Netherlands, 1981.

Heinemeyer, A. and McNamara, N. P.: Comparing the closed static versus the closed dynamic chamber flux methodology: Implications for soil respiration studies, Plant Soil, 346, 145-151, 2011.

Hutchinson, G. L. and Mosier, A. R.: Improved soil cover method for field measurements of nitrous oxide fluxes, Soil Sci. Soc. Am. J., 45, 311-316, 1981.

Keller, M. and Reiners, W. A.: Soil-atmosphere exchange of nitrous oxide, nitric oxide and methane under secondary succession of pasture to forest in the Atlantic downhill of Costa Rica, Global Biogeochem. Cy., 8, 399-409, 1994.

Keller, M., Goreau, T. J., Wofsy, S. C., Kaplan, W. A., and McElroy, M. B.: Production of nitrous oxide and consumption of methane by forest soils, Geophys. Res. Lett., 10, 1156-1159, 1983.

Keller, M., Veldkamp, E., Weitz, A. M., and Reiners, W. A.: Effect of pasture age on soil trace-gas emissions from a deforested area of Costa Rica, Nature, 365, 244-246, 1993.

Keller, M., Weitz, A. M., Bryan, B., Rivera, M. M., and Silver, W. L.: Soil-atmosphere nitrogen oxide fluxes: effects of roots disturbance, J. Geophys. Res., 105, 17693-17698, 2000.

Keller, M., Varner, R., Dias, J. D., Silva, H., Crill, P., and de Oliveira, R. C.: Soil-atmosphere exchange of nitrous oxide, nitric oxide, methane, and carbon dioxide in logged and undisturbed forest in the Tapajos National Forest, Brazil, Earth Interact., 9, 1-28, 2005.

Kiese, R. and Butterbach-Bahl, K.: $\mathrm{N}_{2} \mathrm{O}$ and $\mathrm{CO}_{2}$ emissions from three different tropical forest sites in the wet tropics of Queensland, Australia, Soil Biol. Biochem., 34, 975-987, 2002.

Kiese, R., Hewett, B., Graham, A., and Butterbach-Bahl, K.: Seasonal variability of $\mathrm{N}_{2} \mathrm{O}$ emissions and $\mathrm{CH}_{4}$ uptake in tropical rainforest soils of Queensland, Australia, Global Biogeochem. Cy., 17, 1043, doi:10.1029/2002GB002014, 2003.

Kiese, R., Li, C., Hilbert, D., Papen, H., and Butterbach-Bahl, K.: Regional application of PnET-N-DNDC for estimating the $\mathrm{N}_{2} \mathrm{O}$ source strength of tropical rainforests in the Wet Tropics of Australia, Glob. Change Biol., 11, 128-144, 2005.

Koehler, B., Corre, M. D., Veldkamp, E., Wullaert, H. S., and Wright, J.: Immediate and long-term nitrogen oxide emissions from tropical forest soils exposed to elevated nitrogen input. Global Change Biol., 15, 2049-2066, 2009.

Kort, E. A., Patra, P. K., Ishijima, K., Daube, B. C., Jiménez, R., Elkins, J., Hurst, D., Moore, F. L., Sweeney, C., and Wofsy, S. C.: Tropospheric distribution and variability of $\mathrm{N}_{2} \mathrm{O}$ : evidence for strong tropical emissions, Geophys. Res. Lett., 38, L15806, doi:10.1029/2011GL047612, 2011.

Liu, J., Jiang, P., Wang, H., Zhou, G., Wua, J., Yang, F., and Qian, X.: Seasonal soil $\mathrm{CO}_{2}$ efflux dynamics after land use change from a natural forest to Moso bamboo plantations in subtropical China, Forest Ecol. Manag., 262, 1131-1137, 2011.

Livingston, G. P., Vitousek, P. M., and Matson, P. A.: Nitrous oxide fluxes and nitrogen transformations across a landscape gradient in Amazonia, J. Geophys. Res., 93, 1593-1599, 1988.

Loftfield, N., Flessa, H., Augustin, J., and Beese, F.: Automated gas chromatographic system for rapid analysis of the atmospheric 
trace gases methane, carbon dioxide and nitrous oxide, J. Environ. Qual., 26, 560-564, 1997.

Luizao, F., Matson, P. A., Livingston, G., Luizao, R., and Vitousek, P. M.: Nitrous oxide flux following tropical land clearing, Global Biogeochem. Cy. 3, 281-85, 1989.

Maddock, J. E. L., Bernadete, M., dos Santos, P., and Prata, K. R.: Nitrous oxide emission from soil of the Mata Atlantica, Rio de Jeneiro State, Brasil, J. Geophys. Res., 106, 23055-23060, 2001.

Mapanda, F., Mupinib, J., Wutab, M., Nyamangara, J., and Rees, R. M.: A cross-ecosystem assessment of the effects of land cover and land use on soil emission of selected greenhouse gases and related soil properties in Zimbabwe, Eur. J. Soil Sci., 61, 72733, 2010

Matson, P. A. and Vitousek, P. M.: Cross-system comparison of soil nitrogen transformations and nitrous oxide fluxes in tropical forests, Global Biogeochem. Cy., 1, 163-170, 1987.

Melillo, J. M., Steudler, P. A., Feigl, B. J., Neill, C., Garcia, D., Piccolo, M. C., Cerri, C. C., and Tian, H.: Nitrous oxide emissions from forests and pastures of various ages in the Brazilian Amazon, J. Geophys. Res., 106, 34179-34188, 2001.

Mikutta, R., Kleber, M., Kaiser, K., and Jahn, R.: Review: organic matter removal from soils using hydrogen peroxide, sodium hypochlorite, and disodium peroxodisulfate, Soil Sci. Soc. Am. J., 6, 120-135, 2005.

Muoghalu, J. I., Akanni, S. O., and Eretan, O. O.: Litter fall and nutrient dynamics in a Nigerian rain forest seven years after a ground fire, J. Veg. Sci., 4, 323-328, 1993.

Nepstad, D. C., Moutinho, P., Dias-Filho M. B., Davidson, E., Cardinot, G., Markewitz, D., Figueiredo, R., Vianna, N., Chambers, J., Ray, D., Guerreiros, J. B., Lefebvre, P., Sternberg, L., Moreira, M., Barros, L., Ishida, F. Y., Tohlver, I., Belk, E., Kalif, K., and Schwalbe, K.: The effects of partial throughfall exclusion on canopy processes, aboveground production, and biogeochemistry of an Amazon forest, J. Geophys. Res., 107, 8085, doi:10.1029/2001JD000360, 2002.

Sousa Neto, E., Carmo, J. B., Keller, M., Martins, S. C., Alves, L. F., Vieira, S. A., Piccolo, M. C., Camargo, P., Couto, H. T. Z., Joly, C. A., and Martinelli, L. A.: Soil-atmosphere exchange of nitrous oxide, methane and carbon dioxide in a gradient of elevation in the coastal Brazilian Atlantic forest, Biogeosciences, 8, 733-742, doi:10.5194/bg-8-733-2011, 2011

Potter, C. S., Matson, P. A., Vitousek, P. M., and Davidson, E. A. Process modelling of controls on nitrogen trace gas emissions from soils world-wide, J. Geophys. Res., 101, 1361-1377, 1996.

Rayment, M. B. and Jarvis, P. G.: An improved open chamber system for measuring soil $\mathrm{CO}_{2}$ effluxes in the field, J. Geophys. Res.-Atmos., 102, 28779-28784, 1997.

Serca, D., Delmas, R., Jamnert, C., and Labroue, L.: Emissions of nitrogen oxides from equatorial rain forest in Central Africa: origin and regulation of $\mathrm{NO}$ emission from soils, Tellus B, 46, 243 $254,1994$.
Smith, K. A.: Anaerobic zones and denitrification in soil: modelling and measurements, in: Denitrification in Soil and Sediment, edited by: Revsboech, N. P. and Sørensen, J., Plenum Press, New York, 228-240, 1990.

Smith, K. A., Clayton, H., McTaggart, I. P., Thomson, P. E., Arah, J. R. M., and Scott, A.: The measurement of nitrous oxide emissions from soil by using chambers, Philos. T. Roy. Soc. B., 51, 327-338, 1995.

Sotta, E. D., Meir, P., Mahli, Y., Nobrez, A. D., Hodnett, M., and Grace, J.: Soil $\mathrm{CO}_{2}$ efflux in a tropical forest in the Central Amazon, Glob. Change Biol., 10, 601-617, 2004.

Stehfest, E. and Bouwman, L.: $\mathrm{N}_{2} \mathrm{O}$ and $\mathrm{NO}$ emission from agricultural fields and soils under natural vegetation: summarizing available measurement data and modeling of global annual emissions, Nutr. Cycl. Agroecosys., 74, 207-228, 2006

Verchot, L. V., Davidson, E. A., Cattânio, J. H., Ackerman, I. L., Erickson, H. E., and Keller, M.: Land use change and biogeochemical controls of nitrogen oxide emissions from soils in eastern Amazonia, Global Biogeochem. Cy., 13, 31-46, 1999.

Verchot, L. V., Hutabarat, L., Hairiah, K., and van Noordwijk, M.: Nitrogen availability and soil $\mathrm{N}_{2} \mathrm{O}$ emissions following conversion of forests to coffee in Southern Sumatra, Global Biogeochem. Cy, 20, GB4008, doi:10.1029/2005GB002469, 2006.

Wang, Y., Wang, Y., and Ling, H.: A new carrier gas type fro accurate measurement of $\mathrm{N}_{2} \mathrm{O}$ by GC-ECD, Adv. Atmos. Sci., 27 , 1322-1330, 2010.

Weitz, A. M., Veldkamp, E., Keller, M., Neff, J., and Crill, P. M.: Nitrous oxide, nitric oxide and methane fluxes from soils following clearing and burning of tropical secondary forest, J. Geophys. Res., 103, 28047-28058, 1998.

Werner, C., Kiese, R., and Butterbach-Bahl, K.: Soil-atmosphere exchange of $\mathrm{N}_{2} \mathrm{O}, \mathrm{CH}_{4}$, and $\mathrm{CO}_{2}$ and controlling environmental factors for tropical rain forest sites in western Kenya, J. Geophys. Res., 112, D03308, doi:10.1029/2006JD007388, 2007a..

Werner, C., Butterbach-Bahl, K., Haas, E., Hickler, T., and Kiese, R.: A global inventory of $\mathrm{N}_{2} \mathrm{O}$ emissions from tropical rainforest soils using a detailed biogeochemical model, Global Biogeochem. Cy., 21, GB3010, doi:10.1029/2006GB002909, 2007b.

Werner, C., Zheng, X., Tang, J., Xie, B., Liu, C., Kiese, R., and Butterbach-Bahl, K.: $\mathrm{N}_{2} \mathrm{O}, \mathrm{CH}_{4}$ and $\mathrm{CO}_{2}$ emissions from seasonal tropical rainforests and a rubber plantation in South West China, Plant Soil, 289, 335-353, 2006.

Yan, Y., Sha, L., Cao, M., Zheng, Z., Tang, J., Wang, Y., Zhang, Y., Wang, R., Liu, G., Wang, Y., and Sun, Y.:: Fluxes of $\mathrm{CH}_{4}$ and $\mathrm{N}_{2} \mathrm{O}$ from soil under a tropical seasonal rain forest in Xishuangbanna, Southwest China, J. Environ. Sci., 20, 207-215, 2008.

Yan, J., Zhang, D., Zhou, G., and Liu, J.: Soil respiration associated with forest succession in subtropical forests in Dinghushan Biosphere Reserve, Soil Biol. Biochem., 41, 991-999, 2009. 